\title{
Anatomical study of canthal index: The morphometrical study
}

\section{Yadav SK', Malla BK², Srivastava AK ${ }^{3}$, Kumar Alok ${ }^{4}$}

'Sanjay Kumar Yadav, Lecturer, ${ }^{2}$ Banshi Krishna Malla, Associate Professor, Department of Anatomy, Kathmandu Medical College, Kathmandu, Nepal; ${ }^{3}$ Ashok Kumar Srivastava, Professor, Department of Anatomy, Saraswati Medical and Dental College, Lucknow, India; ${ }^{4}$ Alok Kumar, Professor, Department of Forensic Medicine \& Toxicology, Uttar Pradesh University of Medical Sciences, Saifai, India.

\begin{abstract}
Background: Anthropometry is the hallmark technique for biological anthropometry and has become increasingly important in health assessment across this century. Craniofacial anthropometry is study of face and skull. The local data on inner canthal distance, outer canthal distance and canthal index may signify the differential developmental pattern resulting from various factors such as gender, age, genetic and climate and may help in craniofacial surgery, orthodontists, congenital anomalies and forensic science.

Objectives: The objective of the study is to compare anthropometric dimension related to inner canthal distance, outer canthal distance and canthal index.

Methodology: The outer and inner canthal measurements of Nepali population wereobserved in 318 normal male and female. Out of total samples, 156 male and 162 female of age 17 - 25 years were taken for study since study was done in medical college preclinical students. The inner and outer canthal distances were measured by using a digital sliding caliper graduated in millimeters. The Canthal index was calculated.

Results: There was statistically significant difference in inner canthal distance among female (31.84 \pm 2.22$) \mathrm{mm}$ and male (34.48 \pm 3.35$) \mathrm{mm}(\mathrm{P}<0.001)$. We found statistically significant difference in the outer canthal distance among female $94.30 \pm 3.42 \mathrm{~mm}$ and male $96.54 \pm 4.77 \mathrm{~mm}(P<0.001)$; moreover, there was significance difference in mean canthal index among female and male $(33.77 \pm 2.42$ and $35.79 \pm 3.76 ; \mathrm{P}<0.001)$ respectively.

Conclusion: This work has generated normative values for canthal dimensions of Nepali population. The study would be of benefit not only to anthropometrist, oral and maxillofacial surgeons, plastic surgeons, forensic medicine, but also to orthodontists and dysmorphologists.
\end{abstract}

Key words: Anthropometry; Canthal index; Dysmorphologist; Inner canthal distance; Orthodontist; Outer canthal distance.

DOI: https://doi.org/10.3126/jkmc.v8i3.29718

\section{INTRODUCTION}

raniofacial anthropometry is defined as the measurements of medial (inner), lateral (outer) canthal distance and canthal index. It is very important for the study of human growth,variation in different races for clinical diagnosis and treatment as described by Poswillo'. Anthropometry is concerned with

Address for correspondence

Mr. Sanjay Kumar Yadav

Lecturer, Department of Anatomy

Kathmandu Medical College Teaching Hospital,

Kathmandu, Nepal

E-mail: biraj.sanjay@gmail.com

ORCID:https://orcid.org/0000-0002-9233-765X measurement of physical size and shape of human body $^{2}$. Craniofacial anthropometry is an integral part of craniofacial surgery and syndromology ${ }^{3}$. It is a technique used in both physical and clinical anthropology comprising precise and systematic measurements of the human skull. It is important for the study of human growth and variations in different races and also for clinical diagnosis and treatment that people with different genetic background subjected to significantly different environmental influences have different craniofacial morphology ${ }^{4}$.

The face is a complex anatomic unit. It is best to evaluate each distinct region of the face separately 
taking care to relate the various parts to the whole. Canthal dimensions are important anthropometric data of clinical significance. Though facial measurements have been performed since Greek era, only recently its significance has been appreciated ${ }^{5,6}$. Inner canthal and outer canthal dimensions are important measurements in the evaluation of several systemic syndromes, craniofacial abnormalities and surgical treatments of post-traumatic canthus ${ }^{7}$. Dysmorphologist employs canthal measurements in evaluating the degree of hypertelorism. Accurate values of these distances are essential guide to both constructive surgery and orthodontic treatment. Deformities of the face are most often congenital but may result from trauma, burns, neoplasm or any pathology involving the facial skeleton $^{8}$.

By implication, it may not be unlikely that it may vary with climatic conditions or ecological habitat of one human population to another. Normative canthal values that serve as guide in medical intervention for conditions that may concern the facial canthus are available for Mexicans and Japanese ${ }^{9}$. It is also known that in a given individual, canthal values vary with age, and tend to become constant in the mid to late twenties ${ }^{5}$. The aim of the study is to find out the anthropometric variation in inner canthal distance, outer canthal distance and canthal index among male and female of age group 1725 years old in Nepali population.

\section{CLINICAL SIGNIFICANCE OF CANTHAL PARAMETERS}

The evaluations of canthal parameters is helpful for the craniofacial dimorphic in individual with syndromic conditions. The report on canthal parameter is significant for the unaffected family requiring genetic counseling as requirement for screening procedure and also has importance for craniofacial assessment, surgery and forensic science in the Nepali population.

\section{METHODOLOGY}

The cross-sectional study was conducted in the department of Anatomy of Kathmandu Medical College, Duwakot, Bhaktapur, Nepal from August 2018 to December 2018. Preclinical medical students attending KMCTH were taken for the study. A total number of 318 medical students of both sexes were taken, out of which 156 were male and 162 were female. Ethical clearance was taken from the IRC of Kathmandu Medical College. Healthy individuals were taken for sample and individualswith chronic, debilitating diseases, congenital and acquired deformities, participants having family history of intercaste marriage (due to possibility of change in face morphology)and foreign students were excluded from study. All parameters were measured by digital Vernier calliper. All canthal parameters were taken in millimeter $(\mathrm{mm})$.

The different parameters in the study are Inner canthal distance (ICD) and Outer canthal distance (OCD). ICD is the distance measured from the medial angle of the palpebral fissure to median angle palpebral fissure while OCD is the distance measured from the outer edge of the bony orbit to outer edge as shown fig. $1^{12}$.

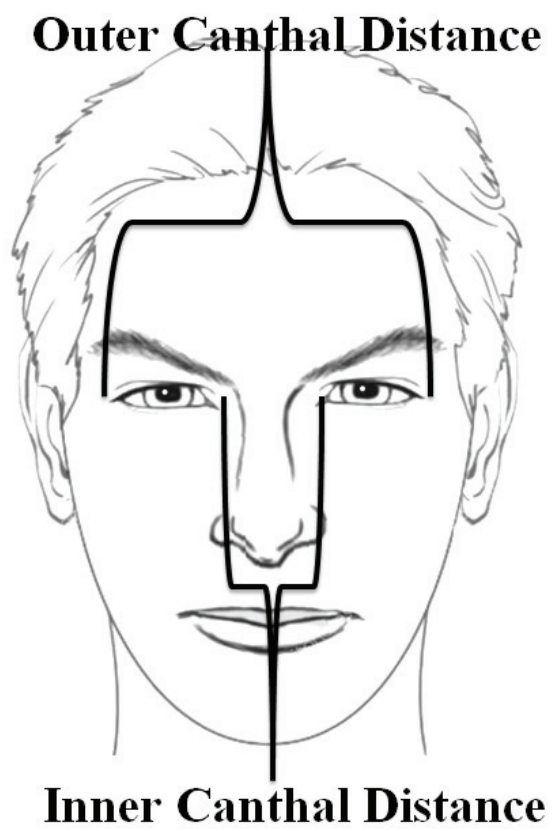

Figure 1: Measurement of different parameters used in the study ${ }^{4}$

Mathematically, Canthal index is the ratio of inner canthal distance to outer canthal distance multiplied by $100^{12}$.

For statistical analysis, mean, standard deviation, standard error and p-value were calculated by using Statistical Package for Social Science (SPSS) version 22 as statistical software and using t- test for calculation of canthal parameters.

\section{RESULTS}

The results obtained after the statistical analysisamong male and female of Nepali population. On comparing mean values of all parameters among male and female, result showed that values of ICD, OCD and CI were higher in male than female and observed statistically significant $(p<0.001)$ as shown in table 1. 
Table 1: Canthal parameters among Nepali people

\begin{tabular}{lccc}
\hline Parameters & Male & Female & P-Value \\
Inner Canthal Distance & Mean \pm SD & Mean \pm SD & 0.001 \\
Outer Canthal Distance & $34.48 \pm 3.36 \mathrm{~mm}$ & $31.84 \pm 2.22 \mathrm{~mm}$ & 0.001 \\
Canthal Index & $96.54 \pm 4.78 \mathrm{~mm}$ & $94.30 \pm 3.42 \mathrm{~mm}$ & 0.001 \\
\hline
\end{tabular}

Table 2: Comparisons of canthal parameters with other study

\begin{tabular}{|c|c|c|c|c|}
\hline Study by & Sex & ICD (Mean \pm SD) mm & OCD (Mean \pm SD) $\mathrm{mm}$ & $\mathrm{Cl}($ Mean $\pm \mathrm{SD})$ \\
\hline \multirow{2}{*}{ Juberg et al. (1975) African-American ${ }^{10}$} & Male & ---------------- & ---------------- & 38.38 \\
\hline & Female & 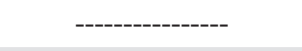 & -------------- & 38.50 \\
\hline \multirow{2}{*}{ Singh \& Banerjee (1983) Indian ${ }^{11}$} & Male & ---------------- & ---------------- & 37.23 \\
\hline & Female & --------------- & ---------------- & 37.82 \\
\hline \multirow{2}{*}{ Cem et al. (2001) Turkish ${ }^{12}$} & Male & 28.33 & 81.74 & 34.66 \\
\hline & Female & 28.14 & 81.17 & 34.60 \\
\hline \multirow{2}{*}{ Erika et al. (2005) Latvian, Nigeria ${ }^{13}$} & Male & ---------------- & ---------------- & 27.38 \\
\hline & Female & 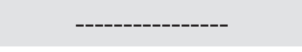 & --------------- & 26.44 \\
\hline \multirow{2}{*}{ Oladipo et al.(2008) Ijaw, Nigeria ${ }^{14}$} & Male & ---------------- & ---------------- & 37.04 \\
\hline & Female & ---------------- & --------------- & 33.11 \\
\hline \multirow{2}{*}{ Oladipo et al. (2008) Igbo, Nigeria ${ }^{14}$} & Male & 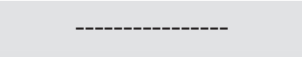 & --------------- & 35.14 \\
\hline & Female & ---------------- & ---------------- & 32.59 \\
\hline \multirow{2}{*}{ Oladipo et al. (2009) Urhobo, Nigeria ${ }^{15}$} & Male & 34 & 131 & 29.38 \\
\hline & Female & 30 & 121 & 26.03 \\
\hline \multirow{2}{*}{ Oladipo et al. (2009) Itsekiri, Nigreia ${ }^{15}$} & Male & 35 & 129 & 27.70 \\
\hline & Female & 33 & 114 & 31.64 \\
\hline \multirow{2}{*}{ Jaja BNR et al (2011) Nigeria, Kalabari ${ }^{16}$} & Male & $18.5 \pm 0.30$ & $103.9 \pm 0.56$ & 17.84 \\
\hline & Female & $20.7 \pm 0.29$ & $104 \pm 0.98$ & 20.08 \\
\hline \multirow{2}{*}{ Oladipo et al (2011) Ibibio, Nigeria ${ }^{4}$} & Male & $35.2 \pm 0.27$ & $111.5 \pm 0.51$ & $31.64 \pm 2.57$ \\
\hline & Female & $33.6 \pm 0.30$ & $107.3 \pm 0.63$ & $31.47 \pm 4.62$ \\
\hline \multirow{2}{*}{ Osunwoke EA(2012) ljaws ${ }^{17}$} & Male & $33.68 \pm 4.18$ & $97.86 \pm 4.41$ & $34.25 \pm 3.57$ \\
\hline & Female & $31.14 \pm 3.30$ & $97.20 \pm 3.62$ & $32.02 \pm 3.24$ \\
\hline \multirow[t]{2}{*}{ Anibor E. (2014) Isokos ${ }^{18}$} & Male & $36.98 \pm 1.96$ & $106.17 \pm 3.73$ & $35.58 \pm 0.96$ \\
\hline & Female & $34.63 \pm 2.98$ & $107.13 \pm 2.98$ & $34.64 \pm 0.83$ \\
\hline \multirow{2}{*}{ Adhikari et al (2016)Nepalese ${ }^{19}$} & Male & $33.37 \pm 0.33$ & $93.5 \pm 0.66$ & $36.62 \pm 5.65$ \\
\hline & Female & $31.7 \pm 0.30$ & $91.5 \pm .35$ & $34.62 \pm 3.20$ \\
\hline \multirow{2}{*}{ Present Study (2018) } & Male & $34.48 \pm 3.36$ & $96.54 \pm 4.78$ & $35.79 \pm 3.76$ \\
\hline & Female & $31.84 \pm 2.22$ & $94.30 \pm 3.42$ & $33.77 \pm 2.42$ \\
\hline
\end{tabular}

\section{DISCUSSION}

Craniofacial anthropometry is important tool for clinician, genetics and reconstructive surgeon. Somatometric trait of face such telecanthus, epicanthaus, widely separated eyebrows and ocular adnexal may create some illusion during the diagnosis of craniofacial syndromes and may required appropriate method of identification of some facial anomalies ${ }^{7,9}$.
In the present study, overall innercanthal distance, outercanthal distance and canthal index were found to higher in male than female at $P$ - Value $<0.001$. Osunwoke EA (2012) observed and tabulated that ICD, OCD and $\mathrm{Cl}$ among male and female were $33.68 \pm 4.18 \mathrm{~mm}$, $97.86 \pm 4.41 \mathrm{~mm}, 34.25 \pm 3.57 \mathrm{~mm}$ and $31.14 \pm 3.30 \mathrm{~mm}$, $97.20 \pm 3.62,32.02 \pm 3.24$ respectively ${ }^{17}$. In compare to present study the values of canthal measurements were significantly higher in Nepali populations as shown in 
table 3. Our study is consistence with studies done by Osunwoke EA and Anibor $\mathrm{E}^{17,18}$. The various study showed that mean values of $I C D, O C D$ and $C I$ were higher in male than female. The present study also showed male had greater values of ICD, OCD and $\mathrm{Cl}$ than female and our study was consistent with majority of studies.

Cemet al.,(2001) in Turkey, reported that the inner canthal distance, outer canthal distance and canthal index for Turkish male was greater than those of female ${ }^{12}$. In the present study values of the inner, outer canthal distance and canthal indexin male is greater than female. We were found again significantly higher in all parameters.

Oladipo et al., 2011 observed similar parameter in Ibilio, Nigeria and found ICD, OCD and $\mathrm{Cl}$ to be greater in maleas compared to female population'. The value of canthal parameters was higher in ICD, OCD and lesser $\mathrm{Cl}$ than present study. Adhikari et al., (2016) reported that ICD, OCD and $\mathrm{Cl}$ observed among male and female respectively and were found higher in ICD and $\mathrm{Cl}$ but lesser $\mathrm{OCD}^{19}$. $\mathrm{Cl}$ can be influenced by OCD if value of $O C D$ is greater the canthal index is lesser. These variations were found to be due climate, environment, ethnicity and genetics of facial development.

Oladipoet al., (2008) reported that the mean value of canthal index in male ljaws and lgbos were the greater than female ljaws and Igbos $^{14}$. Oladipo et al., (2009) in population Urhobo found that canthal index - in malewas greater than female. Oladipo et al., (2009) Itsekiri also did similar studies and found canthal index of malewas less than female population ${ }^{12,15}$. In both the

\section{REFERENCES}

1. Pryor HB. Objective measurement of interpupillary distance.Pediatr.1969; 44:973-7.

2. Henry Gray: Gray's Anatomy Churchill and Livingstone. $38^{\text {th }}$ ed. 1995.p.432-5.

3. Ulijaszek SJ, Lourie JA. Anthropometry in health assessement. The importance of measurement error. Coll Anthropol. 1997; 2: 429-38.[PubMed]

4. Oladipo GS, Akande PA, Osogba IG, Yorkum KL. Anthropometric Studies of Inner Canthal Distance, Outer Canthal Distance and Canthal Index of Adult Ibibios. Asian J Med Sci.2011; 3(1): 14-6.

5. Fledalius HC, Stubgard M. Changes in eye position during growth and adult life as based on exophthalmomentry interpupillary distance and orbital distance measurement. Acta Ophtamal. 1986; 64:481-6.[DOI] studies the values of canthal index was higher in female than in male individual.

The studies conducted by Oladipo et al., in 2008 and 2009 in different places showed that the canthal index among male and female were lesserthan our study which showed the canthal index value for male and female population as $35.79 \pm 3.76$ and $33.77 \pm 2.42$ respectively. In present study canthal index was higher in male than female and canthal index in both sexes were higher in Nepali populations than Urhobo and Itsekiri. The present study was contrary to studies done by Oladipo et al., (2009) among Urhobo and Itsekiri of Nigeria and also Juberg et al., in African- American (1975) Cl: 38.38 male and 38.50 female $^{10}$ and Singh and Banerjee (1983) Cl: 37.23 male and 37.82 female in Indian. The values canthal parameters and other craniofacial indices are influence by environment, geographical and genetically between and within the populations ${ }^{11}$.

\section{CONCLUSION}

We concluded that environment, geographical, gender, ethnicity and genetic are responsible for variation in different parameter of craniofacial anthropometry. The present study is of high relevance to genetic anthropology, forensic anthropology, medical anthropology and also valuable in canthal anthropometry for formulation of normal data in the Nepal. The study is of immense value for further investigation in different domains of Nepal like clinical practice, ophthalmology, forensic anthropology, genetic developmental anatomy for facial anomaly and paleoanthropological studies.

6. Feingold $\mathrm{M}$, Bossert WH. Normal values for selected physical parameter: An aid to delineation. Birth defects. 1974; 10:1-15.[PubMed]

7. Farkas LG, Hreozko TM, Katic MJ, Fornest CR. Proportion indices in the craniofacial regions of 284 healthy North American white children of 1 and 5 years of age. J Craniofac Surg. 2003;14:13-28.[DOI]

8. Oyinbo AC, Fawehinmi BH, Dare WN, Berezi AM. Normal Outer and Canthal Measurements of the ljaws of Southern Nigeria.Eur J Sci Res. 2008; 22:1637.

9. Laestadius ND, Aese JM, Smith DN. Normal canthal and orbital dimensions.J Pediatr. 1969; 74:465-8. [DOI]

10. Juberg RC, Sholte FG, Touchstone WJ. Normalvalues for intercanthal distances of 5 to 11 year old American blacks. Pediatr. 1975; 55(3):431-6. 
11. Singh JR, Banerjee S. Normal values of interpupillary, intercanthal and outer canthal distances in an Indian population. Hum Hered. 1983; 33(5):326-8. [DOI]

12. Cem E, Cengiz Y, Hamdi E, Selim D, Yasar D. Normative values of craniofacial measurements in idiopathic benign microcephalic children. The Cleft Palate CraniofacJ. 2001; 38(3):260-3.[DOI]

13. Erika N,UldisT,Dzintra K.Craniofacial anthropometry in a group of healthy Latvian residents. Acta Medica Lituanica. 2005; 12(1): 47-53.

14. Oladipo GS, Olotu EJ, Gwurineama IU. Anthropometric comparison of Canthal Indices between the ljaw and Igbo tribes. Scientia Africana. 2008; 7(1):141-4.

15. Oladipo GS, Fawehinmi HB, Okoh PD. Canthal indices of Urhobo and Itsekiri ethnic groups. AJBAS. 2009; 3(4): 3093-6.
16. Jaja BNR, Fawehinmi HB, Jack JT. Craniofacial anthropometry in a young Nigerian population: the canthal distances. Int J Morphol. 2011; 29(3):914-7. [DOI]

17. Osunwoke EA, Didia BC, Olotu EJ, Yerikema $A H$. A study on the normal values of inner canthal, outer canthal, interpupillary distance and head circumference of 3-21 years ljaws. Am J Sci Ind Res.2012; 3(6):441-5.[DOI]

18. Anibor E, Omokaro E,Ofere F. Variations in canthal index of the Isokos in Delta State.IJBAIR. 2014; 3(4): 143-6.

19. Adhikari N, Ambekar MN, KC S. An Anthropometric Comparison of Inner Canthal Distance, Outer Canthal Distance and Canthal Index in the Indian and Nepalese Undergraduate Students of Nepalgunj Medical College. JNGMC. 2016 Dec;14 (2):12-4.[DOI] 